\title{
Assessment of Quality Indexes in Colonoscopy in the Coloproctology Service of a Tertiary Private Hospital in Southern Brazil
}

\section{Avaliação de índices de qualidade em colonoscopia em um serviço de coloproctologia de um hospital terciário privado do Sul do Brasil}

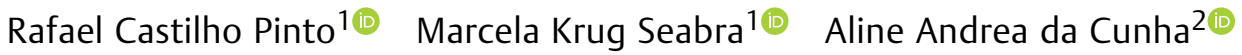 \\ Cassia Garcia Moraes Pagano ${ }^{20}$ Heloisa Guedes Mussnich ${ }^{10}$ \\ ${ }^{1}$ Coloproctology Service, Hospital Moinhos de Vento, Porto Alegre, \\ RS, Brazil \\ 2 Research Support Center, Hospital Moinhos de Vento, Porto Alegre, \\ RS, Brazil \\ J Coloproctol 2021;41(1):23-29. \\ Address for correspondence Rafael Castilho Pinto, MD, Rua \\ Tiradentes 333, 120 andar, Hospital Moinhos de Vento, Porto Alegre, \\ RS, Brazil (e-mail: rafaelpinto266@gmail.com).
}

\begin{abstract}
Keywords

- adenoma

- colorectal cancer

- colonoscopy

Background Colorectal cancer (CRC) is the third most common cancer among men, and the second among women worldwide. In Brazil, the incidence and mortality of CRC continues to increase. In colonoscopies, adenoma detection rates (ADRs) higher than $25 \%$ are associated linearly with better outcomes and lower rates of interval cancer. Objective To assess the colonoscopy quality indexes.

Methods This is a cross-sectional retrospective study in which anatomopathological data and data regarding the colonoscopies were collected from the patient records of Hospital Moinhos de Vento, in Southern Brazil. The exams were performed by doctors from the Colorectal Service from June to August 2015.

Results A total of 430 exams were included. Most patients were women (60.9\% [262]), with a mean age of 56.96 years. The cecal intubation rate was of $96.7 \%$ (416). The quality of the bowel preparation was excellent or good in $92.95 \%$ (396) of the cases. The average time of removal of the colonoscope in normal exams was of 6.15 minutes. Polyps were detected in 201 patients (46.7\%), and adenomas, in 125 patients (29.1\%); 12 patients (2.8\%) had advanced adenomas, and $6(2.3 \%)$ had malignant neoplasms. The proximal serrated lesion detection rate (PSLDR) was of $6.7 \%$ (29). The prevalence ratio (PR) of adenomas among men was 1.78 times greater than in women (95\% confidence interval [95\% CI]: 1.16-2.75). The PR of adenomas among people aged 50 years or older was 2.41 times that of those under 50 years of age (95\% Cl: $1.43-4.06)$.
\end{abstract}

received July 14,2020 accepted August 11, 2020
DOI https://doi.org/ 10.1055/s-0041-1724070. ISSN 2237-9363. (c) 2021. Sociedade Brasileira de Coloproctologia. All rights reserved.

This is an open access article published by Thieme under the terms of the Creative Commons Attribution-NonDerivative-NonCommercial-License, permitting copying and reproduction so long as the original work is given appropriate credit. Contents may not be used for commercial purposes, or adapted, remixed, transformed or built upon. (https://creativecommons.org/ licenses/by-nc-nd/4.0/)

Thieme Revinter Publicações Ltda., Rua do Matoso 170, Rio de Janeiro, RJ, CEP 20270-135, Brazil 


\section{Resumo}

\author{
Palavras-chave \\ - adenoma \\ - câncer colorretal \\ - colonoscopia
}

Conclusion The data obtained are in line with international quality criteria in colonoscopy. More studies are needed to assess the ADR in the Brazilian population.

Introdução O câncer colorretal (CCR) é o terceiro mais comum em homens e o segundo mais comum em mulheres em todo o mundo. A incidência e mortalidade do CRC continuam a aumentar no Brasil. Taxas de detecção de adenoma superiores a 25\% em colonoscopias estão associadas linearmente a melhores resultados e menores taxas de câncer de intervalo.

Objetivo Avaliar a qualidade das colonoscopias analisadas.

Métodos Este é um estudo transversal e retrospectivo no qual dados anatomopatológicos e relacionados às colonoscopias foram coletados de registros dos pacientes do Hospital Moinhos de Vento, no Sul do Brasil. Os exames foram realizados por médicos do Serviço de Coloproctologia de junho a agosto de 2015.

Resultados Foram incluídos 430 exames. A maioria dos pacientes era do sexo feminino (60,9\% [262]), com idade média de 56,96 anos. A taxa de intubação cecal foi de 96,7\% (416). A qualidade do preparo intestinal foi excelente ou boa em $92,95 \%$ (396) dos casos. 0 tempo médio de retirada do colonoscópio em exames normais foi de 6,15 minutos. Pólipos foram detectados em 201 pacientes (46,7\%), e adenomas, em 125 (29.1\%); 12 pacientes (2,8\%) tinham adenomas avançados, e 6 (2,3\%), neoplasias malignas. A taxa de detecção de lesões serrilhadas foi de 6,7\% (29). A razão prevalência (RP) de adenomas em homens foi de 1,78 vezes em relação a mulheres (intervalo de confiança de $95 \%$ [IC95\%]: 1,16-2,75). A RP de adenomas entre pacientes com 50 anos ou mais foi 2,41 vezes maior do que a daqueles com mais de 50 anos (IC95\%: 1,43-4,06).

Conclusão Os dados obtidos estão de acordo com os critérios internacionais de qualidade em colonoscopia. Mais estudos são necessários para avaliar as taxas de detecção de adenoma na população brasileira.

\section{Introduction}

Colorectal cancer (CRC) is one of the most frequent tumors in the world, the third most common among men and the second among women. The prevention and early detection of this disease require more effective strategies, especially in developing countries. ${ }^{1,2}$ In Brazil, the incidence and mortality of CRC continues to increase, and the highest rates are found in the Southern and Southeastern regions of the country (23.90 new cases per 100 thousand inhabitants per year among men, and 21.30 new cases per 100 thousand inhabitants per year among women in the State of Rio Grande do Sul, Southern Brazil). This incidence is similar to that of developed countries, whose screening strategies are already well-established. ${ }^{3,4}$

Colonoscopy is widely used for the diagnosis and treatment of colon disorders. One of the most important exams when screening for colon disorders, it is generally safe, accurate, and well-tolerated, it is and it is very important to measure quality indexes based on established international criteria. ${ }^{5-7}$ Missing lesions on colonoscopy are the most frequent cause of interval cancer, and a high-quality colonoscopy decreases the chance of missing or misdiagnosing existing lesions. ${ }^{8,9}$

The adenoma detection rate (ADR) is one of the main quality parameters in colonoscopy. ${ }^{5-7}$ Reference services in CRC screening should have ADRs in colonoscopies higher than $20 \%$ to $30 \%$, for they are linearly associated with better outcomes and lower rates of interval cancer. ${ }^{10,11}$ In 2015 , the American Society for Gastrointestinal Endoscopy (ASGE) suggested in its guidelines that referral services in CRC screening should have ADRs higher than $20 \%$ among women and 30\% among men. ${ }^{5}$ The European Society of Gastrointestinal Endoscopy (ESGE) guidelines, based on recent population-based studies, proposed a minimum standard ADR of $25 \%(7,12)$, which was met by the majority of endoscopists. ${ }^{7}$ Recent studies with new advanced imaging equipments have shown even higher ADRs, inferring that, with the dissemination of these new technologies, the minimum ADR standards may become even higher in the near future. ${ }^{12}$

Several interventions, including education, raising awareness, feedback and benchmarking on colonoscopy quality have all helped to improve the ADR for colonoscopists involved in screening programs. ${ }^{13,14}$ The other main criteria associated with ADRs are quality of the preparation, cecal intubation and the time of removal of the colonoscope in normal colonoscopies. The optimal effectiveness of the colonoscopy depends on the acceptance of the procedure by the patient, which depends mostly on the acceptance of the bowel preparation. ${ }^{5,6}$ In this context, the ESGE recommends that endoscopic services should have a minimum of $\geq 90 \%$ of all colonoscopies and a target of $\geq 95 \%$ in screening procedures with adequate bowel 
preparation, $^{7}$ and the ASGE recommends that the percentage of outpatient examinations with inadequate bowel preparation should not exceed $15 \%{ }^{5,15,16}$

The time of removal of the colonoscope in normal exams provides information about the time that endoscopists spend identifying the pathology. Meticulous inspection and longer removal times are associated with higher ADRs., ${ }^{5,17,18} \mathrm{~A}$ mean removal time $>6$ minutes has been associated with higher ADRs. 19

Cecal intubation is another important quality criterion. The ASGE and ESGE suggest that effective colonoscopists should reach cecal intubation in $90 \%$ of the cases, and in $95 \%$ of the cases when the indication is screening, and photographs of the landmarks should be taken in every procedure. $5,7,20$

The authors of the present study believe that all endoscopists and endoscopic services should measure the quality of their colonoscopies because data shows that services in which the ADRs are measured and the doctors are trained to achieve higher ADRs get better results in subsequent measurements. ${ }^{14}$ But there are still few studies in Brazil analyzing quality indexes in colonoscopy, and more data is required in order to establish the adequate ADR to be sought in our population. There is also a need to measure the ADR in populational CRC screening programs to better assess the impact of this strategy on our reality, as well as the economic viability of these programs.

The main objective of the present study is to assess the quality indexes of the colonoscopies performed by the doctors of a coloproctology service of a private tertiary hospital. In addition, these quality parameters were correlated with the demographic data of this population.

\section{Methods}

The present is a cross-sectional retrospective study in which Anatomopathological data and data regarding the colonoscopies were collected from the electronic medical records of patients from Hospital Moinhos de Vento, in Southern Brazil. The exams were performed by 31 doctors from the Colorectal Service from June to August 2015. The present study was evaluated and approved by the Ethics in Research Committee (ERC) of the aforementioned hospital under the registration number CAEE 48565915.3.0000.5330.

The patients who underwent colonoscopies in the selected period were included in the study. The exams of the patients whose doctors did not agree to participate in the study were excluded.

All colonoscopies were performed with the Olympus (Shinjuku, Tokyo, Japan) CV-180 Evis Exera II equipment, with the patients under anesthesia and having signed the informed consent form. The usual bowel preparation at our hospital is with 4 tablets of bisacodyl the day before the examination, together with mannitol in a concentration of $20 \%$ diluted in $500 \mathrm{~mL}$ of clear liquid on the day of the examination, but the doctors could offer any personalized preparation for their individual patients.

The data on age and gender were collected from the medical records, as well as data regarding the indication for the exam, which was classified as prevention, polyp control, cancer control, other symptoms and not reported. Ragarding age, the patients were divided into the following groups: $<40$ years; 40 to 49 years; 50 to 59 years; 60 to 69 years; and $\geq 70$ years of age.

We collected data from the colonoscopic written and the photographic register preparation quality regarding the time of removal of the colonoscope in normal exams, the immediate complications, the detection rate and location of the polyps in the colon, the ADR, sessile serrated adenoma/polyp detection rate (SSA/PDR), and malignant neoplasia.

The quality of the bowel preparation was classified into four categories according to the Aronchik scale: excellent (minimal presence of residues with small quantities of clear liquid requiring suction); good (small amount of fecal waste with moderate or large amount of liquid requiring suction); fair (presence of semi-solid wastes that are difficult to completely remove by suction); and inadequate (presence of solid or semi-solid wastes that cannot be adequately removed, preventing the progression of the exam). ${ }^{21}$

The removal time was measured in normal exams as the difference between the tome of the cecum photography and that of the rectum photography. Regarding location, the left colon contained polyps in the rectum, sigmoid colon and descending colon, whereas the right colon contained polyps in the cecum, transverse colon, and ascending colon. The polyps were histologically classified as hyperplastic, lowgrade adenoma, advanced adenoma (villous adenoma, tubulovillous adenoma, and high-grade dysplasia), and serrated polyps. The polyps with more than $10 \mathrm{~mm}$ were considered advanced adenomas. We consider to this study to calculate the serrated lesions rate we used the SSA/PDR and rightsided hyperplastic polyps (RHPDRs) that constitute the proximal serrated lesion detection rate (PSLDR). ${ }^{22}$

The data regarding the patients were compiled in Microsoft Excel (Microsoft Corp., Redmond, WA, US) for Windows and for Macintosh 2011, version 14.4.3, spreadsheets, and they were analyzed using the Statistical Package for the Social Sciences (SPSS, IBM Corp. Armonk, NY, US) for Windows, version 21.0. Descriptive analyses were used to characterize the study population, such as absolute and percentage frequency for the categorical variables, mean and standard deviation for the continuous variables. The Pearson Chi-squared test was used to assess the differences between the groups. Poisson regression with robust variance was used to estimate the prevalence ratio regarding adenoma detection and predictors (gender and age group). The significance level of $5 \%$ was adopted in the analyses.

\section{Results}

In total, 430 out of the 647 colonoscopies performed between June and August 2015 were analyzed in the present study. - Table 1 shows the demographic characteristics of the patients, as well as the indication for the exam and the quality of the bowel preparation. Most patients were women (60.9\%), with a mean age of 56.96 years (standard deviation [SD]: \pm 13.88 years). In most cases, the indication for the colonoscopy was for screening (45.3\%). The percentage of patients who underwent procedures during the colonoscopy 
Table 1 Demographic characteristics and general aspects of colonoscopies in the evaluated sample $(n=430)$

\begin{tabular}{|c|c|c|}
\hline Variable & $\mathrm{N}$ & $\%$ \\
\hline \multicolumn{3}{|l|}{ Gender } \\
\hline Female & 262 & 60.9 \\
\hline Male & 168 & 39.1 \\
\hline \multicolumn{3}{|l|}{ Age (in years) } \\
\hline$<40$ & 51 & 11.9 \\
\hline $40-49$ & 76 & 17.7 \\
\hline $50-59$ & 106 & 24.6 \\
\hline $60-69$ & 119 & 27.7 \\
\hline$\geq 70$ & 78 & 18.1 \\
\hline \multicolumn{3}{|c|}{ Indications for the colonoscopy } \\
\hline Screening & 195 & 45.3 \\
\hline Polyp or cancer control & 78 & 18.1 \\
\hline Others & 92 & 21.4 \\
\hline Not described & 65 & 15.1 \\
\hline \multicolumn{3}{|c|}{ Quality of the bowel preparation * } \\
\hline Excelent & 313 & 73.47 \\
\hline Good & 83 & 19.48 \\
\hline Fair & 22 & 5.16 \\
\hline Inadequate & 8 & 1.8 \\
\hline \multicolumn{3}{|l|}{ Procedures } \\
\hline No & 180 & 41.9 \\
\hline Polipectomy & 241 & 56.0 \\
\hline Others & 9 & 2.1 \\
\hline
\end{tabular}

Note: ${ }^{*} \mathrm{n}=426$. In four patients, it was not possible to assess the quality of the bowel preparation.

was of $58.1 \%$, and $56.1 \%$ of the procedures were polypectomies. The bowel preparation quality was excellent or good in $92,95 \%$ (396) of the cases. There were no immediate complications described in the evaluated exams.

The cecal intubation rate was of $96.7 \%$ (416): in 5 exams (1.2\%), there was an obstructive lesion; in $6(1.4 \%)$, inadequate preparation prevented the tube from reaching the cecum; and in $3(0.7 \%)$ exams, technical difficulties prevented the tube from reach the cecum.

The removal time was evaluated in 143 out of the 180 patients with normal exams, with an average time of 6.15 minutes (SD: \pm 3.04 minutes). Of these patients, 55.9\% (80) had removal times $\geq 6$ minutes. In 37 (20,55\%) colonoscopies, the photographic record did not enable the establishment of the removal time.

-Table 2 shows the detection rates of the polyps and adenomas. Polyps were detected in 201 patients (46.7\%), and adenomas, in 125 (29.1\%) patients. Of these patients, 12 (2.8\%) had advanced adenomas, and 6 (2.3\%), malignant neoplasms.

The ADR was significantly higher in the right colon in relation to the left colon (19.3\% versus $16.3 \%$ respectively; $p<0.001$ ).
Table 2 Detection rates of polyps and adenomas $(n=430)$

\begin{tabular}{|l|l|l|}
\hline Variable & $\boldsymbol{n}$ & $\%$ \\
\hline Polyp & 201 & 46.7 \\
\hline Adenoma & 125 & 29.1 \\
\hline Advanced adenoma & 12 & 2.8 \\
\hline Malignant neoplasia & 6 & 2.3 \\
\hline
\end{tabular}

Table 3 Detection rate of proximal serrated lesions $(n=430)$

\begin{tabular}{|l|l|l|}
\hline & $\boldsymbol{n}$ & $\%$ \\
\hline $\begin{array}{l}\text { Proximal serrated lesion detection rate: } \\
\text { sessile serrated adenoma /polyp detection } \\
\text { rate + right-sided hyperplastic polyp } \\
\text { detection rate }\end{array}$ & 29 & 6.7 \\
\hline $\begin{array}{l}\text { Sessile serrated adenoma /polyp detection } \\
\text { rate }\end{array}$ & 15 & 3.5 \\
\hline $\begin{array}{l}\text { Right-sided hyperplastic polyps detection } \\
\text { rate }\end{array}$ & 20 & 4.7 \\
\hline
\end{tabular}

Table 4 Adenoma detection rate according to colonoscopy indication $(n=430)$

\begin{tabular}{|l|l|l|}
\hline Colonoscopy indication & $\begin{array}{l}\text { Adenoma } \\
\text { detection rate } \\
\text { n (\%) }\end{array}$ & \multirow{2}{*}{0.059} \\
\cline { 1 - 2 } Screening & $61(31.3)$ & \\
\cline { 1 - 2 } Cancer or polyp control & $31(39.7)$ & \\
\cline { 1 - 2 } Other & $21(22.8)$ & \\
\cline { 1 - 2 } Not described & $15(23.1)$ & \\
\hline
\end{tabular}

Note: *Pearson Chi-squared test; significance level of 0.05 .

The SSA/PDR) was of 3.5\% and the PSLDR was of $6.7 \%$, as shown in - Table 3.

The ADR was higher among patients who underwent the examination for cancer or polyp control (39.7\% [31 patients]), followed by patients who underwent it for screening (31.3\% [61 patients]). However, this difference was not statistically significant (table 4).

- Table 5 presents data on ADR according to gender and age group. The ADR was higher among men (35.7\%; $p=0.016)$, and it rose with increasing age $(p=0.004)$.

The prevalence ratio (PR) of adenomas among men was 1.78 times than in women (95\% confidence interval $[95 \% \mathrm{CI}]$ : 1.16-2.75). Comparing patients aged 50 years or older with those younger than that, the ADR was of $33.77 \%$ and $18.11 \%$ respectively, with a PR of more than 2.41 times higher among the older patients (95\% CI: $1.43-4.06$ ).

\section{Discussion}

Despite the high incidence and mortality of CRC in Southern Brazil, ${ }^{3,4}$ the present study is one of the first of its kind performed in our state. The assessment of quality parameters 
Table 5 Adenoma detection rate according to gender and age $(n=430)$

\begin{tabular}{|c|l|c|}
\hline \multirow{2}{*}{ Variable } & Adenoma detection rate & \multirow{2}{*}{$*^{*}$} \\
\cline { 2 - 2 } & $\mathbf{n}(\%)$ & \\
\hline Gender & & \multirow{2}{*}{0.016} \\
\hline Female & $65(24.9)$ & \\
\hline Male & $60(35.7)$ & \multirow{2}{*}{0.004} \\
\hline Age (in years) & & \\
\hline$<40$ & $6(11.8)$ & \\
\hline $40-49$ & $17(22.4)$ & \\
\hline $50-59$ & $29(27.6)$ & \\
\hline $60-69$ & $43(36.1)$ & \\
\hline$\geq 70$ & $30(38.5)$ & \\
\hline
\end{tabular}

Note: *Pearson Chi-squared test; significance level of 0.05.

in colonoscopy is not yet routine in endoscopic digestive services in Brazil.

In the present study, the detection rate of polyps was of $46.7 \%$, and the general ADR was of $29.1 \%$, reaching $35.7 \%$ (60) among women and $24.9 \%$ (65) among men. These results show that our ADR by gender is similar to that of developed countries, and they are in accordance with the established quality criteria in colonoscopy established by the ASGE and the ESGE. ${ }^{5,7}$ The ADR is the main quality criterion in colonoscopy, and the minimum quality levels have been increased in the last 10 years by the ASGE from $15 \%$ to $20 \%$ in women and from 20 to $30 \%$ in men. ${ }^{5,6}$

The findings of the present study validate the applicability of these global targets in the Southern Region of Brazil. Regarding other regions of the country, a study conducted in the Midwestern region by Cardoso et al., ${ }^{23}$ found an ADR of $27.1 \%$ in colonoscopies performed for screening, with $25.3 \%$ among women and $30.6 \%$ among men. Another study, which was also conducted in Southern Brazil, but in the state of Santa Catarina, by Fiorentin et al., ${ }^{24}$ found a general ADR of $19.8 \%$ in a private clinic.

To achieve high ADRs, we need to understand whether other quality criteria in colonoscopy are appropriate, and where we can improve to further increase our ADR targets. $5,7,25$ Bowel preparation is an important quality parameter. In the present study, the quality of the bowel cleaning was excellent or good in $92.95 \%$ of the exams, according the Aronchik scale, ${ }^{21}$ and the performance of the colonoscopy was possible in $98.2 \%$ (418) of the cases, meeting the criteria established by the ASGE and the ESGE. ${ }^{5,7}$ But we should also point out that the routine use of more reproducible scales, such as the Boston scale, to measure the quality of the preparation can result in better rates. ${ }^{26,27}$

Another favorable factor was the high rates of cecal intubation, an essential quality parameter, especially regarding the detection of adenomas in the right colon, because the initial studies $^{28,29}$ on the effectiveness of decreasing incidence and mortality of cancer in the right colon were not as favorable as those regarding the left colon. Since the measurement of the rates of cecal intubation has become routine worldwide, the results of screening strategies have also shown a significant improvement in the detection of adenomas in the right colon. ${ }^{28-30}$ In the present study, the rate of cecal intubation was very high, reaching $99.6 \%$ of the colonoscopies excluding those with obstructed lesions or those in which inadequate bowel preparation made it impossible to reach the cecum.

In association with the high rate of cecal intubation rate, the ADR in the right colon was good in comparison to that of the left colon: $19.3 \%$ versus $16.3 \%$ respectively. An elevated ADR in the right colon is an important factor in the improvement of results regarding the incidence and mortality in cases of cancer in the right colon, and it is also associated with good-quality preparation and a high rate of cecal intubation. ${ }^{28,29}$ An issue that could be associated with poor-quality colonoscopy in the right colon is that lesions use to be flatter and quality of the bowel preparation could have greater interference in the detection of these polyps. ${ }^{30}$

Some authors ${ }^{22,29}$ correlate the good quality of the colonoscopy with a proper PSLDR, mainly in the right colon. In a study conducted in Australia, the authors suggested to considering a minimum PSLDR of $4.5 \%{ }^{22}$ In the present study, the PSLDR was of $6.7 \%$. This is another important factor when looking for favorable results in screening for right colon cancer. ${ }^{22,31}$ On the other hand, one of the criteria that could be improved in our institution is the removal time in normal exams. The average removal time in the present study was of 6.15 minutes, but there is still a good proportion of exams (44,1\% [63]) in which the removal time was shorter than the minimum 6 minutes recommended by the ASGE and ESGE guidelines. The literature $e^{5,7,17,19}$ suggests that increasing the removal time above the six-minute target could lead to an additional gain in ADR.

Age is one of the most important risk factors in CRC, and several studies ${ }^{5,7}$ and guidelines ${ }^{32-34}$ suggest starting screening programs in the population aged $>50$ years. In the present study, an association was also observed between ADR and age group, which was of $11.8 \%$ among patients younger than 40 years of age, and getting at $38.5 \%$ among those aged $>70$ years. The ADR of patients aged $>50$ years was of $33.77 \%$, when categorized into two groups, and the ratio of prevalence comparing patients with less than 50 years with those above 50 years was 2.41 . This data could suggest that, as in other countries, 50 years could be the age to start screening the population in our region. ${ }^{32-34}$

In this study, there was no follow-up data to enable us to obtain data regarding interval cancer and mortality, but some studies $^{11,14,35}$ have shown that ADRs higher than those suggested in international criteria are related to lower rates of interval cancer and decrease mortality in long-term follow-up.

The present study has limitations; since it was retrospective, it contains all the drawbacks inherent in this type of study. Since our service does not count with a standardized colonoscopic electronic report, some data were missing, mainly regarding the indication for the colonoscopy and the removal time in normal exams. Another caveat from this study is not consider only preventive colonoscopies to calculate the ADR, but considering that there is no statistical 
difference among the groups of indication we assumed the ADR for all indications groups to do our statistical analysis.

Regardless of the limitations, it was very important to confirm that the criteria proposed for quality in colonoscopy by the ESGE and ASGE guidelines were met in the studied population. But the data, which was extracted from a tertiary private hospital with endoscopists experienced in the procedure, cannot be generalized to the rest of the country or even to our region. We need to have more quality data from colonoscopies in our region, mainly in the public health service, to guide future screening strategies. Nonetheless, the data obtained in the present study are compatible with international quality criteria in colonoscopy. More studies are needed to assess the ADR in the Brazilian population and to compare it with the international indexes already established in the literature. This could provide more scientific support to plan screening strategies in our country and to reach the goal of reducing the incidence, mortality and costs involving CRC in Brazil.

Authors' contributions:

Pinto, RC: study design, data collection and analysis, preparation and revision of the manuscript; Seabra MK: study design and data collection; Cunha, AAd, and Pagano, CGM: statistical analysis and preparation and revision of the manuscript. Mussnich HG: study design and revision of the manuscript.

Conflict of Interests:

The authors have no conflict of interests to declare.

\section{Acknowledgments}

We would like to thank the doctors at the Coloproctology Service, as well as the scientific support provided by the team working at the Center for Research Support (Núcleo de Apoio à Pesquisa, in Portuguese) of Hospital Moinhos de Vento.

\section{References}

1 WHO. The Global Cancer Observatory - Colorectal Cancer. 2018 [Available from: February 2019. http://gco.iarc.fr/today/data/ factsheets/cancers/10_8_9-Colorectum-fact-sheet.pdf

2 Siegel RL, Miller KD, Jemal A. Cancer statistics, 2020. CA Cancer J Clin 2020;70(01):7-30

3 INCA. Estimativa 2020: incidência de câncer no Brasil. 2019 [Available from: 2019. https://www.inca.gov.br/sites/ufu.sti. inca.local/files//media/document//estimativa-2020-incidenciade-cancer-no-brasil.pdf

4 Oliveira RC, Rêgo MA. Mortality risk of colorectal cancer in Brazil from 1980 to 2013. Arq Gastroenterol 2016;53(02):76-83

5 Rex DK, Schoenfeld PS, Cohen J, et al. Quality indicators for colonoscopy. Gastrointest Endosc 2015;81(01):31-53

6 Rex DK, Petrini JL, Baron TH, et al. Quality indicators for colonoscopy. Gastrointest Endosc 2006;63(4, Suppl):S16-S28

7 Kaminski MF, Thomas-Gibson S, Bugajski M, et al. Performance measures for lower gastrointestinal endoscopy: a European Society of Gastrointestinal Endoscopy (ESGE) quality improvement initiative. United European Gastroenterol J 2017;5(03): 309-334

8 Lieberman DA, Rex DK, Winawer SJ, Giardiello FM, Johnson DA, Levin TR. Guidelines for colonoscopy surveillance after screening and polypectomy: a consensus update by the US Multi-Society
Task Force on Colorectal Cancer. Gastroenterology 2012;143(03): 844-857

9 Robertson DJ, Lieberman DA, Winawer SJ, et al. Colorectal cancers soon after colonoscopy: a pooled multicohort analysis. Gut 2014; 63(06):949-956

10 Corley DA, Levin TR, Doubeni CA. Adenoma detection rate and risk of colorectal cancer and death. N Engl J Med 2014;370(26):2541

11 Kaminski MF, Regula J, Kraszewska E, et al. Quality indicators for colonoscopy and the risk of interval cancer. N Engl J Med 2010;362 (19):1795-1803

12 Oliveira Dos Santos CE, Malaman D, Pereira-Lima JC, de Quadros Onófrio F, Ribas Filho JM. Impact of linked-color imaging on colorectal adenoma detection. Gastrointest Endosc 2019;90 (05):826-834

13 Kaminski MF, Anderson J, Valori R, et al. Leadership training to improve adenoma detection rate in screening colonoscopy: a randomised trial. Gut 2016;65(04):616-624

14 Corley DA, Jensen C, Lee JK, et al. Increasing Physician Adenoma Detection Rate is Associated with a Reduced Risk of PostColonoscopy Colorectal Cancer. Gastroenterology 2019;156 (06):

15 Rex DK, Imperiale TF, Latinovich DR, Bratcher LL. Impact of bowel preparation on efficiency and cost of colonoscopy. Am J Gastroenterol 2002;97(07):1696-1700

16 Froehlich F, Wietlisbach V, Gonvers JJ, Burnand B, Vader JP. Impact of colonic cleansing on quality and diagnostic yield of colonoscopy: the European Panel of Appropriateness of Gastrointestinal Endoscopy European multicenter study. Gastrointest Endosc 2005;61(03):378-384

17 Rex DK. Colonoscopic withdrawal technique is associated with adenoma miss rates. Gastrointest Endosc 2000;51(01):33-36

18 Lin OS, Kozarek RA, Arai A, et al. The effect of periodic monitoring and feedback on screening colonoscopy withdrawal times, polyp detection rates, and patient satisfaction scores. Gastrointest Endosc 2010;71(07):1253-1259

19 Barclay RL, Vicari JJ, Doughty AS, Johanson JF, Greenlaw RL. Colonoscopic withdrawal times and adenoma detection during screening colonoscopy. N Engl J Med 2006;355(24): 2533-2541

20 Belderbos TD, Grobbee EJ, van Oijen MG, et al. Comparison of cecal intubation and adenoma detection between hospitals can provide incentives to improve quality of colonoscopy. Endoscopy 2015;47 (08):703-709

21 Aronchick CA, Lipshutz WH, Wright SH, DuFrayne F, Bergman G. Validation of an instrument to assess colon cleansing. Am J Gastroenterol 1999;94:2667

22 Rosty C, Hewett DG, Brown IS, Leggett BA, Whitehall VL. Serrated polyps of the large intestine: current understanding of diagnosis, pathogenesis, and clinical management. J Gastroenterol 2013;48 (03):287-302

23 Cardoso DMM, Botacin MAS, Mekdessi MA. Adenoma detection rate evaluation and quality of colonoscopy in the center-west region of Brazil. Arq Gastroenterol 2017;54(04):315-320

24 Fiorentin J, Philippi A, Baptista T, Silva Júnior J, Cardoso M, Teixeira HPerfil epidemiológico, achados endoscópicos e controle de qualidade das colonoscopias realizadas em uma clínica de gastroenterologia do município de Criciúma entre março e setembro de 20092011; 30(3):[81-6 pp.]

25 Jover R, Zapater P, Polanía E, et al; COLONPREV study investigators. Modifiable endoscopic factors that influence the adenoma detection rate in colorectal cancer screening colonoscopies. Gastrointest Endosc 2013;77(03):381-389.e1

26 Calderwood AH, Jacobson BC. Comprehensive validation of the Boston Bowel Preparation Scale. Gastrointest Endosc 2010;72 (04):686-692

27 Parmar R, Martel M, Rostom A, Barkun AN. Validated Scales for Colon Cleansing: A Systematic Review. Am J Gastroenterol 2016; 111(02):197-204, quiz 205 
28 Brenner H, Chang-Claude J, Seiler CM, Rickert A, Hoffmeister M. Protection from colorectal cancer after colonoscopy: a population-based, case-control study. Ann Intern Med 2011;154(01): 22-30

29 Bressler B, Paszat LF, Vinden C, Li C, He J, Rabeneck L. Colonoscopic miss rates for right-sided colon cancer: a population-based analysis. Gastroenterology 2004;127(02):452-456

30 Corley DA, Jensen CD, Marks AR. Can we improve adenoma detection rates? A systematic review of intervention studies. Gastrointest Endosc 2011;74(03):656-665

31 Nalankilli K, Huynh XT, Lade S, Stephens M, Hewett R, Moss A. Increasing rates of SSA/P detection in a large open-access Australian colonoscopy cohort. Endosc Int Open 2019;7(03): E310-E316
32 Diamond SJ, Enestvedt BK, Jiang Z, et al. Adenoma detection rate increases with each decade of life after 50 years of age. Gastrointest Endosc 2011;74(01):135-140

33 Lin JS, Piper MA, Perdue LA, et al. Screening for Colorectal Cancer: A Systematic Review for the U.S. Preventive Services Task Force. U.S. Preventive Services Task Force Evidence Syntheses, formerly Systematic Evidence Reviews 2016

34 Koo S, Neilson LJ, Von Wagner C, Rees CJ. The NHS Bowel Cancer Screening Program: current perspectives on strategies for improvement. Risk Manag Healthc Policy 2017;10:177-187

35 Kaminski MF, Wieszczy P, Rupinski M, et al. Increased Rate of Adenoma Detection Associates With Reduced Risk of Colorectal Cancer and Death. Gastroenterology 2017;153(01):98-105 